\title{
Значение трудов С. А. Старостина для компаративистики ${ }^{1}$
}

\author{
Алпатов Владимир Михайлович, Институт языкознания РАН (Москва), \\ Московский государственный университет имени М. В. Ломоносова; v-alpatov@ivran.ru
}

\section{THE IMPORTANCE OF S. A. STAROSTIN'S WORK FOR THE COMPARATIVE LINGUISTICS}

\author{
Vladimir M. Alpatov, Institute of linguistics, RAS (Moscow),
} Lomonosov Moscow State University; v-alpatov@ivran.ru

Сергей Анатольевич Старостин (1953-2005) был выдающимся лингвистом широкого профиля, прежде всего компаративистом. Он занимался многими проблемами, среди которых особое место занимала алтаистика.

Вся жизнь ученого прошла в Москве. Его отец и старший брат были известны как выдающиеся полиглоты. Отец Сергея Анатольевича Анатолий Васильевич Старостин был переводчиком и преподавателем языков, включая таджикский и грузинский. Но если старший Старостин был лишь полиглотом, то Сергей Анатольевич одновременно оказался и талантливым ученым, которому очень помогало знание многих языков.

Его способности проявились необычно рано. На Московскую олимпиаду по языковедению и математике, проводившуюся в МГУ для учеников 9-11 классов, он впервые пришел, учась в 6 классе, и получил вторую премию, а затем до окончания школы четыре раза выигрывал олимпиады. Еще школьником он стал ходить на «взрослый» семинар по ностратическому языкознанию, который вели А. Б. Долгопольский и В. А. Дыбо.

В 1970 г. Старостин окончил школу и поступил на Отделение структурной и прикладной лингвистики МГУ, которое окончил в 1975 г. Там он попал в японскую группу, что сыграло значительную роль в его дальнейшей научной деятельности, которая началась очень рано. Сборник его избранных работ «Труды по языкознанию» [Старостин 2007], изданный посмертно, открывается тезисами доклада на конференции по сравнительно-историческому языкознанию в декабре 1972 г., то есть в девятнадцать лет. В то время Сергей учился на третьем курсе, но в примечаниях к книге сказано, что работа была выполнена первокурсником. Первая большая по объему его публикация, также по японским реконструкциям, вышла в сборнике Института востоковедения в год окончания университета. В 1975 г. по окончании МГУ Старостин был зачислен в аспирантуру Отдела языков Института востоковедения РАН, затем работал в том же отделе до 1992 г.

Безусловно, Старостин мог бы добиться успеха в любой области лингвистики, тем более что в студенческие годы он прошел прекрасную школу в экспедициях А. Е. Кибрика в Дагестане. Там студентов учили записывать в полевых условиях и обрабатывать материал малоизученных или вовсе не изученных языков, уметь работать с конкретными языками и видеть в каждом из них специфическое проявление общих закономерностей человеческого Языка. Полевые исследования помогали и компаративистике: во время экспедиции на Сахалин в 1978 г. Старостин изучал распространенные там корейские диалекты, полученные материалы он затем использовал в алтайских реконструкциях. У Сергея Анатольевича есть и публикации по современным языкам, более всего по японскому. Особенно надо выделить его участие в коллективной грамматике японского языка, готовившейся в Институте востоковедения под редакцией И. Ф. Вардуля. К сожалению, удалось написать лишь первый том [Вардуль, Старостин, Алпатов 2000], где Старостину принадлежат разделы по фонологии и акцентуации, в этих областях он был выдающимся специалистом. Свои разделы он закончил к 1982 г., но книга вышла намного позже. Позднее он должен

\footnotetext{
${ }^{1}$ Работа выполнена при поддержке Российского научного фонда (проект № 20-18-00159), организация, осуществляющая финансирование, - Институт языкознания Российской академии наук (ИЯз РАН).
} 
был участвовать и в «Теоретической грамматике японского языка», но она была подготовлена уже после его смерти; фонетические разделы были написаны П. М. Аркадьевым и мной на основе идей Сергея Анатольевича [Алпатов, Аркадьев 2008]. В 1983 г. для Военного института он написал учебник истории японского языка, до сих пор не изданный; там речь шла и об истории языка письменного периода.

Но более всего ученого влекло сравнительно-историческое языкознание - отрасль науки, сложившаяся и получившая немалые результаты еще в начале XIX в., но до сих пор представляющая собой обширное поле деятельности. Лингвист-компаративист на основе строгой методики сопоставляет известные языки и реконструирует праязык, от которого эти языки произошли. Расцвет сравнительно-исторического языкознания пришелся на XIX в., когда был выработан великий сравнительно-исторический метод, хронологически первый из строгих лингвистических методов. За столетие было установлено и доказано родство многих языков, входящих в большую индоевропейскую семью, однако за ее пределы тогда почти не выходили. Лишь с начала XX в. развернулось интенсивное изучение тюркской, монгольской, тунгусо-маньчжурской, семитской, финно-угорской и других семей. А с начала 60-х гг. ХХ в. в СССР стала активно развиваться так называемая ностратическая гипотеза, согласно которой индоевропейские, тюркские, монгольские, тунгусо-маньчжурские, финно-угорские, дравидийские и еще некоторые языки входят в более древнюю ностратическую макросемью. Эти исследования начал замечательный ученый В. М. Иллич-Свитыч (1934-1966), рано погибший; их продолжили А. Б. Долгопольский (1930-2012) и В. А. Дыбо (р. 1931). Сергей Анатольевич со школьных лет связал жизнь с этим кругом лингвистов, став в нем сначала учеником, потом коллегой, потом лидером.

С 1992 г. Старостин перешел во вновь образованный почти с нуля Российский государственный гуманитарный университет (РГГУ), где собрался возглавляемый им коллектив компаративистов, который мог теперь из неформального превратиться в формальный. Образовался особый центр, фактически небольшой научно-исследовательский институт при университете. В конце жизни Сергей Анатольевич также работал в академическом Институте языкознания, где возглавил центр языков Евразии. В 1997 г. он был избран членом-корреспондентом Российской академии наук.

Сильной стороной деятельности Старостина в последние 10-15 лет жизни, помимо наличия тесно спаянного коллектива единомышленников, было активное использование вычислительной техники. По его собственным воспоминаниям, Старостин впервые сел за персональный компьютер в 1986 г., а к 1993 г. он с участием нескольких своих коллег - лингвистов и программистов - уже разработал компьютерную систему Starling. Над ее совершенствованием он работал до конца жизни. Для каждого изучаемого языка были собраны обширные базы данных. И в Институте востоковедения, и затем в РГГУ ученый занимался самыми разнообразными проблемами компаративистики. Трудно найти языковую семью или группу, родственными связями которой Старостин совсем не интересовался; у него есть публикации по очень многим из них, разумеется, по одним больше, по другим меньше. Пожалуй, он наложил на свои исследования одно ограничение: не выходить за пределы Старого Света, пока со всеми его языками не будет всё ясно; дойти до индейских и австралийских языков он не успел. Есть у Старостина работы и по самой традиционной тематике компаративистов - индоевропеистике, и по реконструкции древнекитайской фонетики (этому были посвящены его кандидатская диссертация, защищенная в 1979 г., и изданная позже книга [Старостин 1989], переведенная на китайский язык), и по афразийским языкам (семитские, берберские, древнеегипетский, некоторые другие языки Африки, в том числе сомали и хауса). Особенно много он писал о языках Северного Кавказа, куда и студентом, и позже ездил в экспедиции; вместе с И. М. Дьяконовым и С. Л. Николаевым [Nikolaev, Starostin 1994] он доказал родство восточно-кавказских (дагестанские, чеченский и др.) и западно-кавказских (абхазский, адыгейский, кабардинский и др.) языков. К этой семье оказались принадлежащими и некоторые древние языки Передней Азии: урартский, хаттский, возможно, этрусский [Дьяконов, Старостин 1988]. Еще он занимался почти вымершей енисейской семьей языков (кетский и ряд уже не существующих языков) и предложил смелую гипотезу о родстве между собой западно- и восточно-кавказских, енисейских и китайско-тибетских языков (синокавказская макросемья). Развитием гипотезы ученый занимался до конца жизни. Безусловно, высказать такую гипотезу мог лишь человек, сам интенсивно занимавшийся всеми тремя сравниваемыми семьями, а такого, кроме Старостина, в мире больше не было. Наконец, надо упомянуть учебник «Сравнительноисторическое языкознание», написанный им совместно с его ученицей С. А. Бурлак (два издания в 2001 и 2005 гг.) [Бурлак, Старостин 2001, 2005].

Особенно много ученый занимался исследованием алтайских языков, включая японский. Первым шагом в студенческие годы стало сопоставительное изучение собственно японских диалектов и диалектов островов Рюкю на крайнем юге Японии; именно этому были посвящены вышеупомянутые работы Старостина-студента. Доклад 19-летнего студента назывался «К проблеме реконструкции праяпонской фонологической системы». Диалекты Рюкю, бесспорно, родственны японским (их иногда включают в 
состав японского языка), но уже в древности значительно от них отличались. Для выявления дальнейших родственных связей японского языка необходимо было восстановить праяпонскую звуковую систему на основе сопоставления японского и рюкюского материала. Первым это стал делать (и тоже в самом начале своей деятельности) Е. Д. Поливанов, ставший основоположником научного компаративного изучения японского языка не только в России, но и в мире. Однако Старостин, основываясь на большем материале, и здесь, и в вопросе о внешних связях японского языка (см. ниже) пересмотрел результаты Поливанова.

После защиты кандидатской диссертации Старостин вернулся к японскому языку, но уже в более широком аспекте, рассматривая вопрос о его родственных связях как часть алтаистики и ностратики. В течение 80-х гг. он работал над книгой «Алтайская проблема и происхождение японского языка». Она вышла в самом конце советской эпохи, весной 1991 г. [Старостин 1991], на ее основе в начале 1992 г. им была защищена докторская диссертация. Даже в дарственных экземплярах своей книги он писал: «С уверенностью в алтайском происхождении японского языка». Уверенности во всём, что он делал, у Старостина всегда было много.

Реконструкции Старостина в данной области собраны в вышеупомянутой книге и в итоговом «Этимологическом словаре алтайских языков», подготовленном им совместно с А. В. Дыбо и О. А. Мудраком и изданном на английском языке [Starostin, Dybo, Mudrak 2003]. Я хочу на примере алтаистических исследований ученого показать общий подход Старостина и его коллектива к сложным проблемам дальнего родства.

Как известно, идея о принадлежности японского языка к алтайской семье, куда входят тюркские, монгольские, тунгусо-маньчжурские языки и, по-видимому, корейский, существовала задолго до Сергея Анатольевича: считается, что ее впервые выдвинул в 1857 г. немецкий ученый А. Боллер. Но потом появилась и другая гипотеза, связывавшая японский язык с австронезийской, или малайско-полинезийской, семьей, к которой принадлежат языки Малайзии, Индонезии и Океании; эту гипотезу выдвинул и пытался доказать Е. Д. Поливанов. В сторону поисков генетических связей именно с этими языками толкали исторические данные: древнейшее население Японских островов, по-видимому, составляли австронезийцы, сходные с аборигенами Тайваня (которые именно поэтому вызвали интерес выдающегося япониста Н. А. Невского), но на рубеже новой эры с континента вторглись кочевники-алтайцы; из смешения двух этносов сложились японцы. Впрочем, Е. Д. Поливанов не отрицал и японо-алтайское родство, считая, что японский язык - смешанный, принадлежащий одновременно к алтайской и австронезийской семьям. Старостин, однако, не признавал возможность смешения языков в принципе. Он исходил из аксиом, которых придерживались и ученые - классики индоевропеистики XIX в. Согласно этим аксиомам, никакой язык не может быть смешанным, а если какой-то народ заимствует большую часть базовой лексики, то происходит не смешение, а смена языка. Так, видимо, и произошло с австронезийскими предками японцев, которые, вобрав в себя численно уступавших им завоевателей, переняли их язык, сохранив в качестве субстрата не только сравнительно небольшую часть лексики, но и фонетический строй исконного языка.

Однако вопрос генетической принадлежности японского языка требовал особого рассмотрения. Были ученые, решительно отвергавшие алтайскую принадлежность японского языка, к ним относился, в частности, Н. Поппе, никогда, впрочем, не анализировавший японский материал. Наконец, как известно, с самими алтайскими языками нет ясности. Если в первой половине XX в. идея о существовании алтайской семьи господствовала, то с 50-х гг., после публикаций Дж. Клосона, среди тюркологов и монголистов стало преобладать мнение о том, что алтайского родства нет, а имеющееся между этими языками сходство - результат поздних контактов.

Старостин с самого начала, исходя из постулата о верности ностратической гипотезы, рассматривал данную проблему как часть ностратической проблемы. Уже В. М. Иллич-Свитыч пришел к выводу о том, что все причисляемые к алтайским языки являются ностратическими (тогда как австронезийские языки туда не входят). Но и среди старших коллег Старостина не было единой точки зрения; так, А. Б. Долгопольский считал, что особой алтайской семьи не было, а ее традиционные ветви - отдельные семьи, входящие в ностратическую макросемью. С чем сравнивать праяпонскую систему, восстановленную Старостиным-студентом, еще надо было разбираться.

Для выяснения родственных связей японского языка нужно было применить методы сравнительноисторического языкознания, что оказывалось сложно сделать из-за отсутствия близкородственных языков. Ученый пересмотрел существовавшие алтайские реконструкции и пришел к выводу, что отдельная алтайская семья действительно существовала, а японский язык представляет собой особую ее ветвь, отделившуюся от других алтайских языков раньше всех остальных, примерно в четвертом тысячелетии до новой эры (этим же временем обычно датируется и время существования индоевропейского праязыка; 
следовательно, алтайский праязык еще древнее). К австронезийской же семье японский язык не относится, хотя с ней имеются сходства, объясняемые контактами и субстратными влияниями в историческое время. Эти выводы - выдающийся вклад в науку о языке, важный и для историков и археологов. Хотя на уровне гипотез и деклараций все эти положения высказывались и до Сергея Анатольевича, но впервые было предъявлено их доказательство (впрочем, и сейчас они признаются не всеми специалистами, на чём я остановлюсь ниже).

Одним из важнейших аспектов, связанных с алтайским родством, было использование метода глоттохронологии, предложенного американским лингвистом М. Сводешем в 40-х гг. ХХ в. и до сих пор вызывающего споры, в том числе и среди алтаистов. Формула Сводеша, как указывают в уже упомянутом учебнике С. А. Старостин и С. А. Бурлак, по происхождению представляет собой «формулу полураспада радиоактивного углерода, используемую при радиоуглеродном датировании в археологии и палеонтологии» [Бурлак, Старостин 2005: 131]. Почему эта формула может работать и на лингвистическом материале, не обосновывалось.

Построения М. Сводеша были основаны лишь на индуктивном обобщении известных ему фактов (или на аналогии с другими науками) и не имели строгого доказательства ни с точки зрения состава базовых значений, ни с точки зрения постоянства изменений соответствующих слов, поэтому многие лингвисты их отвергают, нередко на априорных основаниях. Однако (что вообще обычно в компаративистике) такого рода обобщения, казалось бы, ни на чём не основанные, работали и давали результаты; ниже я еще буду говорить об этом. Правда, оказалось, что формула М. Сводеша «умолаживала» время расхождения языков и требовала коррекции. Кроме того, М. Сводеш считал, что все сто слов из его списка имеют равные шансы замениться другими, что оказалось не так. Помимо канонического списка М. Сводеша, предлагали и другие. С одной стороны, 100 значений расширяли до 110 и даже 200; с другой стороны, коллега Старостина из Ленинграда С. Е. Яхонтов (1926-2018) предложил список из 35 самых устойчивых значений.

Старостин постоянно обращался к методу глоттохронологии, на нем основаны его построения и в области алтаистики, и при изучении других семей. Однако он поправил М. Сводеша, пересмотрев и усложнив его формулу, выделив возмущающие факторы (постоянство смены базовой лексики не соблюдается в случае замены исконного слова на заимствованное) и учитывая различную степень «базовости» лексики: 35-словный список С. Е. Яхонтова, собственный 55-словный список, канонический стословный список, список из 110 слов. Хотя в алтаистике были попытки на основе глоттохронологии показать отсутствие алтайского родства, но, по мнению Старостина, они не были убедительны, а сам он получил иные результаты.

Ученый сопоставил списки базовой лексики для выполненных его предшественниками и частично им скорректированных реконструкций тюркского, монгольского, тунгусо-маньчжурского и корейского праязыков, использовав также новые материалы, в частности корейские, собранные им в 1978 г. на Сахалине. Ему удалось выяснить, что, например, между тюркскими и монгольскими языками в списке М. Сводеша имеется 20 слов общего происхождения, а между монгольскими и корейским - 16. Это вполне соответствует принятым критериям признания таких языков родственными. А поскольку многие исконно общие слова сохранились не во всех ветвях алтайской семьи, то процент общеалтайской базовой лексики оказался еще более значительным. Затем он сопоставил эти реконструкции с собственными реконструкциями праяпонского языка. И обнаружилось, что если исходить из 110-словного списка и учитывать четыре семантических дублета в праяпонском, то, как пишет Старостин в своей книге 1991 г., «среди этих 114 лексем мы имеем 81 лексему алтайского происхождения (среди них 49 с точным семантическим соответствием в одном или нескольких алтайских праязыках и 32 лексемы без такого соответствия, но с достаточно надежной алтайской этимологией)». Это очень большой процент. А с австронезийскими языками у праяпонского обнаруживается только 9 совпадений в базовой лексике, из них лишь три в 35-словном списке, что можно объяснить древними заимствованиями [Старостин 1991: 115].

Не надо думать, что вся деятельность ученого сводилась к использованию и коррекции метода глоттохронологии. Он был нужен для интерпретации реконструированных праформ, а сами эти праформы восстанавливались на базе традиционного сравнительно-исторического метода, разработанного в XIX в. и основанного прежде всего на установлении регулярных фонетических соответствий между родственными языками. Этот метод вызывал критику и в XIX в., и в первой половине XX в., и со стороны дилетантов вроде Н. Я. Марра, и со стороны крупных ученых (И. А. Бодуэн де Куртенэ, Н. Трубецкой), а сейчас на Западе многими третируется. При замечательных результатах, полученных с помощью этого метода, лингвисты отмечали его недоказанность. Например, А. Сеше писал: «Лингвистика фактов сумела самостоятельно пробиться к самым замечательным открытиям. Теоретическая наука лишь следовала за ней». В частности, это относилось к регулярности фонетических законов, не поддающейся «рациональ- 
ному обоснованию», попытки сформулировать которое не увенчались успехом. «И если мы по-прежнему верим в плодотворность этого принципа, то потому, что он существует и приносит пользу, а совсем не потому, что мы его поняли» [Сеше 1908/2003: 43].

Но Старостин, основываясь на замечательных результатах, полученных на основе этого метода, считал «аксиоматику сравнительно-исторического языкознания» незыблемой и применимой к любым языкам. Как пишет в предисловии к однотомнику трудов Старостина Вяч. Вс. Иванов, он «разработал принципы сравнения, пригодные для всех существующих шести-восьми тысяч языков и их главных диалектов и возможных предков» [Иванов 2007: XI]. Старостин, например, считал неправильным варьировать списки базовой лексики для разных культурных ареалов, веря в универсальность компаративной методики, включая глоттохронологию, для любых семей и групп. Исходя из принципов, усвоенных в студенческие годы, он всегда искал подтверждения универсальных законов языка, пусть не всегда такие законы пока что познаны.

Постепенно идеи советской ностратики стали известны за рубежом. Здесь сыграли роль и поездка Старостина на ПИАК (Постоянную международную алтаистическую конференцию) в Ташкенте в 1986 г., и особенно поездка осенью 1988 г. делегации советских ученых, работающих в рамках данного направления, на конференцию в Мичиганский университет в США. Старостин, по возрасту один из самых молодых, стал на ней неформальным лидером. «Десант» советских компаративистов вызвал на Западе несомненный интерес, подогревавшийся тогдашней модой на Россию: там ностратики не было (за исключением ученых, ранее эмигрировавших из (ССР), а компаративистика была во многом другой. Нашим участникам конференции казалось, что теперь их идеи станут мировыми. Но позже выяснилось, что, кроме внешних препятствий, бывают и внутренние

Если в России к концу 90-х годов Сергей Анатольевич стал общепризнанным главой научной школы (знаком признания стало и избрание в академию), то иначе сложилась ситуация в мире. За рубежом ностратику знают лучше, чем большинство других направлений российской лингвистики. И всё равно к ней относятся в лучшем случае как к любопытной экзотике, вряд ли соответствующей языковой реальности, в худшем - как к ошибочному направлению. Причин здесь несколько. Сам факт того, что принципиально новые идеи исходят из России, мода на которую прошла, не способствовал мировому признанию идей Старостина и ностратики в целом. Сыграла, по-видимому, роль и деятельность некоторых эмигрантов из СССР и России. Старостину было проще что-то сделать самому, чем выяснять, что здесь уже сделали другие (эта черта сближала его с Е. Д. Поливановым), хотя предшественники могли добиться существенных результатов и просто знать какие-то факты, которые Старостин не знал. Игнорирование им работ некоторых ученых заочно задевало их. Наконец, специалисты по отдельным языкам и языковым группам, досконально их знающие, могли видеть у него ошибки из-за неучета каких-то данных.

Но, пожалуй, главная причина заключалась в том, что Старостин последовательно стоял на позициях классического сравнительно-исторического языкознания. Сами по себе идеи родства тех или иных языков понятны многим, но в их доказательствах могут разобраться даже не все лингвисты, а лишь те из них, кто овладел сложнейшим сравнительно-историческим методом, который обычно усваивается в юности и требует полной отдачи. Когда-то считалось, что заниматься языкознанием и использовать сравнительно-исторический метод - одно и то же, но Ф. де Соссюр открыл путь к научным исследованиям языка, не требующим владения этим методом. А сейчас на Западе, особенно в США, распространена идея о том, что сравнительно-исторический метод устарел, что родство языков можно доказывать и иными способами, скажем, через массовое фронтальное исследование всей лексики сразу многих сравниваемых языков, без кропотливого установления регулярных соответствий, или же через расшифровку геномов носителей тех или иных языков. Таким лингвистам Старостин мог казаться чуть ли не человеком XIX века, пусть вооруженным современной техникой.

Старостин, однако, не хотел тратить время на споры с оппонентами, предпочитая позитивную деятельность. Возглавив научный коллектив, он уже мог планировать большой объем работы по сравнению гигантского числа языков мира, в идеале (которого Старостин не успел достичь) всех языков. Как он писал в статье 1999 г. «О доказательстве языкового родства», «какие-либо теоретические препятствия на пути дальнейшего сравнения или реконструкции отсутствуют», однако имеются трудности, связанные с большим объемом информации, и нужна «готовность к кооперации со стороны специалистов по отдельным языковым семьям» [Старостин 1999: 65]. С уже сложившимися специалистами, в том числе по алтайским языкам, кооперация получалась редко, но Старостин умел своей харизмой привлекать молодежь. И он один мог держать в голове всю гигантскую работу в целом. В той же статье 1999 г. он писал: «Для оценки родства внутри макросемей типа ностратической большинству специалистов просто не хватает знаний по отдельным семьям» [там же: 58]. А кому, кроме него, таких знаний по-настоящему хватало? Он, несомненно, считал, что его реконструкции отражают «божью правду», как иногда говорят 
американские лингвисты. Как свидетельствуют его ближайшие коллеги, Сергей Анатольевич не верил в бога, но у него существовала абсолютная, прямо религиозная убежденность в том, что всё на самом деле происходило так, как получалось из его реконструкций. Старостин был убежденным сторонником единого происхождения всех языков мира (моногенеза) и всерьез мечтал дойти до реконструкции «языка Адама», именно так он и выражался в выступлениях последних лет. Не успел.

К сожалению, взаимное недопонимание, сложившееся между Сергеем Анатольевичем и рядом алтаистов, проявилось и в том, что после удачного дебюта в Ташкенте в 1986 г. он не участвовал в работе конференций ПИАК. Однако, когда летом 2005 г. ПИАК собрался под Москвой, он все-таки согласился выступить на заседании 11 июля. Доклад не вызвал критики, но в его обсуждении участвовали одни только российские делегаты. Никто не мог думать о том, что это одна из его последних конференций. Вечером 30 сентября сразу после занятия со студентами в РГГУ Старостин скоропостижно умер прямо в здании университета. Вскрытие показало, что у него уже был перенесенный на ногах инфаркт, а причиной смерти стал тромб. Ему было 52 года.

Коллектив, основанный Старостиным, продолжает существовать, в области алтаистики активно работают, в частности, его соавторы по «Этимологическому словарю» А. В. Дыбо и О. А. Мудрак; у них уже есть свои ученики. К сожалению, например, на конференциях ПИАК ностратика опять перестала приветствоваться. Но и книга «Алтайская проблема и происхождение японского языка», и подготовленный с его участием алтайский этимологический словарь, и многие другие труды остаются важными вехами в мировой науке. Вся жизнь Сергея Анатольевича была подчинена большой страсти: дойти до «языка Адама», пусть пока так и неизвестно, был ли он на самом деле.

\section{Литература}

Алпатов, Аркадьев 2008 - Алпатов В. М., Аркадьев П. М. Сведения по фонологии и морфонологии // В. M. Алпатов, П. М. Аркадьев, В. И. Подлесская. Теоретическая грамматика японского языка. Т. 1. М., 2008. С. $35-60$. \{Alpatov V. M., Arkadyev P. M. Data on phonology and morphonology // V. M. Alpatov, P. M. Arkadyev, V. I. Podlesskaya. Theoretical grammar of the Japanese language. Vol. 1. Moscow, 2008. P. 35-60.\}

Вардуль, Старостин, Алпатов 2000 - Вардуль И. Ф., Старостин С. А., Алпатов В. М. Грамматика японского языка. М., 2000. \{Vardul I. F., Starostin S. A., Alpatov V. M. The grammar of the Japanese language. Moscow, 2000.\}

Дьяконов, Старостин 1988 - Дьяконов И. М., Старостин С. А. Хуррито-урартские и восточно-кавказские языки // Древний Восток. Этнокультурные связи. М., 1988. С. 112-163. \{Dyakonov I. M., Starostin S. A. Hurrian-Urartian and East Caucasian languages // Ancient East. Ethnocultural relations. Moscow, 1988. P. 112_163.\}

Иванов 2007 - Иванов Вяч. Вс. Предисловие // C. А. Старостин. Труды по языкознанию. М., 2007. С. VIIIXXVIII. \{Ivanov Vyach. Vs. Introduction // S. A. Starostin. Works on linguistics. Moscow, 2007.\}

Сеше 1908/2003 - Сеше A. Программа и метод теоретической лингвистики. М., 2003. \{Sechehaye A. Programme and method of the theoretical linguistics. Moscow, 2003.\} 1-е изд. $\left\{1^{\text {st }}\right.$ edition $\}$ : Sechehaye A. Programme et méthodes de la linguistique theorique. Psychologie du langage. Paris — Genève, 1908.

Старостин 1989 - Старостин С. A. Реконструкция древнекитайской фонологической системы. M., 1989. \{Starostin $S$. $A$. The reconstruction of the Old Chinese phonological system. Moscow, 1989.\}

Старостин 1991 - Старостин C. A. Алтайская проблема и происхождение японского языка. М., 1991. \{Starostin $S$. A. The Altaic problem and the origins of the Japanese language. Moscow, 1991.\}

Старостин 1999 - Старостин C. А. О доказательстве языкового родства // Типология и теория языка. От описания к объяснению. К 60-летию А. Е. Кибрика. М., 1999. С. 57-69. \{Starostin S. A. Proving Language Relationship // Typology and Theory of Language. From description to explanation. A Festschrift for A. E. Kibrik on his $60^{\text {th }}$ Birthday. Moscow, 1999.\}

Старостин 2007 - Старостин С. A. Труды по языкознанию. M., 2007. \{Starostin S. A. Works on linguistics. Moscow, 2007.\}

Бурлак, Старостин 2001 - Бурлак C. А., Старостин С. А. Введение в лингвистическую компаративистику. М., 2001. \{Burlak S. A., Starostin S. A. Introduction to the comparative linguistics. Moscow, 2001.\}

Бурлак, Старостин 2005 - Бурлак C. А., Старостин С. А. Сравнительно-историческое языкознание. М., 2005. \{Burlak S. A., Starostin S. A. Comparative linguistics. Moscow, 2005.\}

Nikolaev, Starostin 1994 - Nikolaev S. L., Starostin S. A. A North Caucasian Etymological Dictionary. Moscow, 1994.

Starostin S. A., Dybo A. V., Mudrak O. A. An Etymological Dictionary of the Altaic Languages. Vol. 1-3. Leiden Boston, 2003. 